\title{
EFFECT OF DEAN NUMBER ON THE HEAT TRANSFER CHARACTERISTICS OF A HELICAL COIL TUBE WITH VARIABLE VELOCITY \& PRESSURE INLET
}

\author{
Prerana Nashine ${ }^{1}$, Thokchom Subhaschandra Singh ${ }^{2, *}$, Upendra Rajak ${ }^{3}$, Tikendra Nath Verma ${ }^{4}$
}

\begin{abstract}
The heat transfer, friction factor, pressure difference, Nusselt number of a helical coil tube using variable pressure and velocity during inlet for various values of Dean number [ratio of coil diameter (D) to tube diameter (d)] has been studied using commercially available computational tool. A validation is performed using the computational tool through the experimental data and it was observed that the results are in good agreement. The helical coil of 0.3 $\mathrm{m}$ diameter with four (4) turns of inner diameter $0.01 \mathrm{~m}$ with length 3.77 has been modelled, meshed and analyzed for both laminar and turbulent flows of constant wall temperature and heat flux. A grid independence test is also performed. The results show that increase in Dean number increases the heat transfer of the helical tube. The increases in pressure have less effect on heat transfer during laminar flow while adverse effect can be observed during turbulent flow.
\end{abstract}

\section{Keywords: Dean Number, Heat Transfer, Friction Factor, Helical Tubes, Nusselt Number}

\section{INTRODUCTION}

Heat exchangers were an inevitable component in modern mechanical systems. In order to effectively use energy being generated through various methods, various heat exchangers in various forms like, economizer, air preheater, super heater, waste heat recovery boilers, etc were used. Even though heat exchangers serves the purpose of transferring heat from one fluid to another, lack of effective heat transfer results in loss of heat from the fluid and hence useful energy is being wasted. For this reason, various methodologies were being studied and adapted in increasing the heat transfer effectiveness of various heat exchangers. In many cases where experimental study is not feasible or economically viable, numerical study have been forecasted by many researchers to be a useful tool. The thermal performance of vertical spiral ground heat exchangers (GHE) for extracting ground source heat using a heat pump was performed for nine (9) spiral GHE and two (2) u-tube GHE with ore holes, using experimental method and numerical method. The experiment was performed for all the test samples for $150 \mathrm{hrs}$. The results of the experiments were compared with predicted numerical results using commercially available solver COMSOL [1]. Another combined experimental and numerical approach was performed for investigating the heat transfer and friction flow characteristics of three (3) mini channel regenerative heat exchangers with hydraulic diameter of the channels as $1.5,1$ and $0.5 \mathrm{~mm}$. The study was conducted for measuring the transient thermal responses and pressure drop at the outlet and inlet of each of the heat exchangers. The authors concluded that heat exchanger with $0.5 \mathrm{~mm}$ have the highest interstitial coefficient of heat transfer, which can be explained due to the increase in the specific surface area of the heat exchanger [2]. Other combined study suggests that desiccant coated heat exchanger have reduced heat transfer coefficient of $30 \%$, as compared to conventional heat exchangers during heat transfer between air and water. The researchers suggested that the reduction in the heat transfer is due to the resistance provided by the desiccant coating [3]. Corrugated inner tubes with pitch of $5 \mathrm{~mm}$ and depth $1.5 \mathrm{~mm}$ have been found to have the highest heat transfer and Nusselt number subjected to different flow rates of 0.03 to $0.13 \mathrm{~kg} / \mathrm{s}$ and 0.04 to $0.14 \mathrm{~kg} / \mathrm{s}$ for cold and hot fluids respectively. The experimental result is verified by the prediction of artificial neural network (ANN) which have R2 values of 0.99999, 0.999997 and 0.999993 for heat transfer, Nusselt number and Reynolds number respectively [4].

This paper was recommended for publication in revised form by Regional Editor Baha Zafer

${ }^{1}$ Department of Mechanical Engineering, National Institute of Technology Rourkela, India

2 Department of Mechanical Engineering, National Institute of Technology Manipur, India

${ }^{3}$ Department of Mechanical Engineering, Rajeev Gandhi Memorial College of Engineering and Technology, Nandyal, India

${ }^{4}$ Department of Mechanical Engineering, Maulana Azad National Institute of Technology Bhopal, India

*E-mail address: th.subhas143@gmail.com, th.s.singh@nitmanipur.ac.in

Orcid id: 0000-0002-6555-3306, 0000-0002-6176-8211, 0000-0002-3884-8758

Manuscript Received 19 July 2018, Accepted 22 November 2018 
The thermo hydraulic performance of air to water heat exchange on a double pipe heat exchanger with helical fins (with fin spacing in the range of 0.05 to $2 \mathrm{~m}$ ) was studied using commercially available numerical solver ANSYS FLUENT [5]. The study have concluded that helical fin with fin spacing of $0.1 \mathrm{~m}$ provides the optimum thermo hydraulic performance. The study also denotes the improvement of compactness and overall performance with use of helical fins. Another study using the software proposed that helical wire inserts can increase the Nusselt number by 1.77 times. Some studies also suggested that circular obstacles in heat exchangers can increase the overall performance, compared to other form of obstacles like rectangular or triangular [6-7]. A study using CFD-segmented heat exchanger model using open sourced solver Open FOAM have recommended that velocity scaling between different fin geometries must be avoided. The maximum capacity loss observed was $9.75 \%$ from bare-tube heat exchangers. They have concluded that the severity of the Mal-distribution of the refrigerant leads to larger capacity loss in heat exchangers [8]. Other applications of CFD can be found in solving complex equations and geometry of internal combustion engines. CFD solver such as Forte Reaction Design (Chemkin) has been used for studying 3dimension simulations of reactions. Engine emissions simulations were effectively being predicted using numerical solver also [9-10]. Other studies on heat exchangers using commercial codes have been extensively studied by various researchers [11-18 16] for different applications. They have found that commercial CFD codes and tools can be used for studying the characteristics of heat exchangers. Other study involves thermal analysis and multi dimensional modeling of various thermal systems including IC engines, emission dispersion studies, slurry flow, flame study thermal comfort etc. [17-33].

In view of the above literatures, the authors have found that there are fewer studies in the combined effect of Dean number, velocity and pressure inlet with conditions of constant wall temperature and heat flux on the heat transfer, friction factor, pressure difference and Nusselt number of a helical tube. Hence a correlative study on the combined effects has been studied numerically using commercially available tool, ANSYS. To increase the accuracy in predicting the results, a validation has been performed using experimental results and the prediction holds good for both values of heat transfer co-efficient and Nusselt number.

\section{METHODOLOGY}

\section{Model Preparation and Geometry Creation}

The helical tube has been modeled using commercial computational tool, ANSYS for which the dimensions of 0.3 meter, 3.77 meter and 0.01 meter for diameter of coil (D), length of tube (L) and diameter of tube (d), has been chosen for the study as shown in Fig. 1, since the present study will be helpful in analyzing compact heat exchange systems. During the process of the study, four (4) other models were also created by changing the value of 'd', keeping constant value of $\mathrm{D}$ and $\mathrm{L}$ in order to effectively study the effect of the change in dean number $(\mathrm{D} / \mathrm{d})$ on the heat transfer and fluid flow characteristics. The circles are initially created and SWEEP procedure is followed for generating the three dimensional model. The number of turns has been specified to be as four, while defining the body type to be fluid for outer and innermost tube and solid for middle tube. The domain or the cell zone conditions of the model have been defined as water- fluid \& copper- solid. The tube of the heat exchanger is made up of copper to facilitate maximum heat transfer due to its superior thermal conductivity. The properties of copper remained constant throughout the analysis.

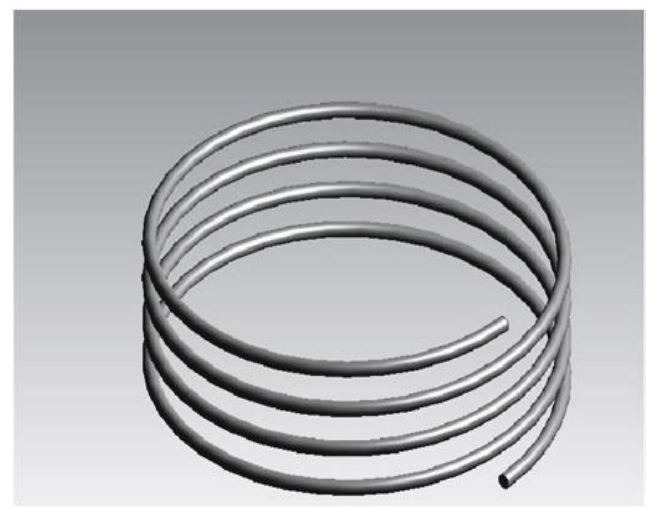

Figure 1. Helical coiled tube designed using commercial computational tool 
The model is meshed using rectangular cells and grid independence test (GIT) was conducted on the model while considering the model with no cells. Fig. 2 shows the meshing of the model in the computational domain.
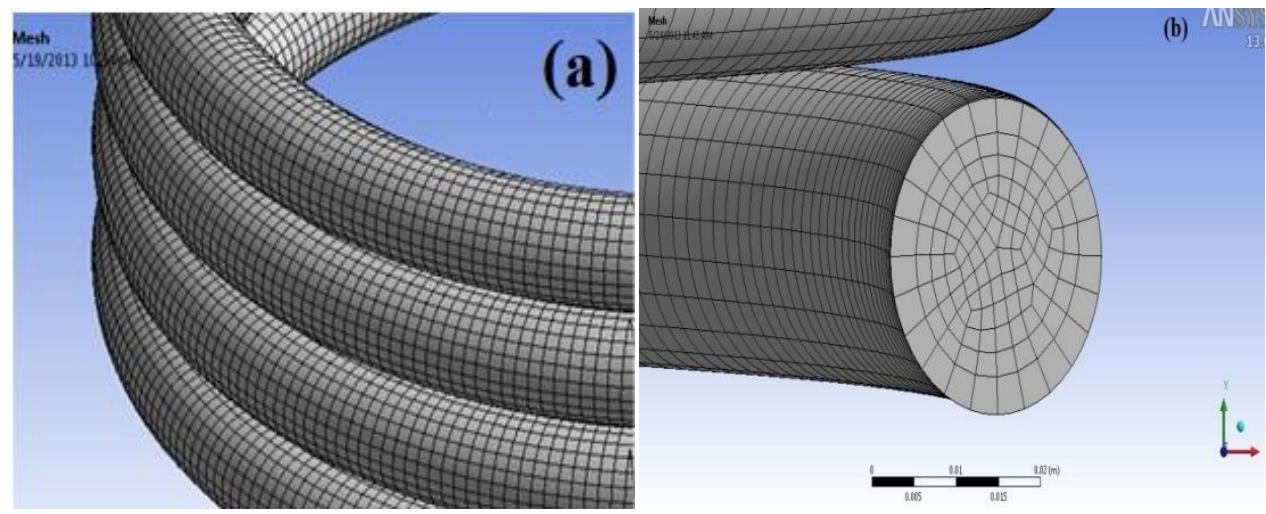

Figure 2. (a) Grid of the computational domain and (b) frontal view of the meshing

\section{Grid Independence Test (GIT)}

Grid independence tests are one of the most vital procedures which are mandatory in numerical problems, for checking the independence of the final results to the number of grids. Since, most of the results being generated are a function of the number of grids being generated; the results vary in accordance to the grids being specified. Hence, the minimum number of grids after which there is no change in the results of the problem is generally referred to as optimum grid size. At this stage, the results are independent of the grids.

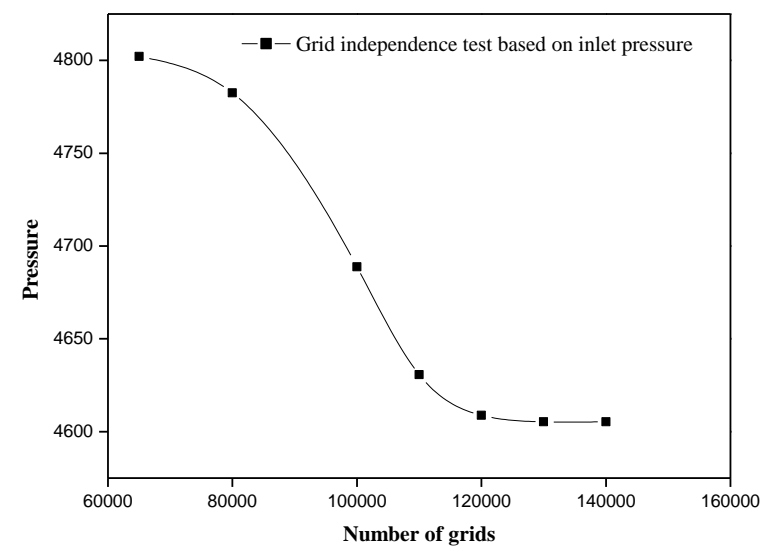

(a)

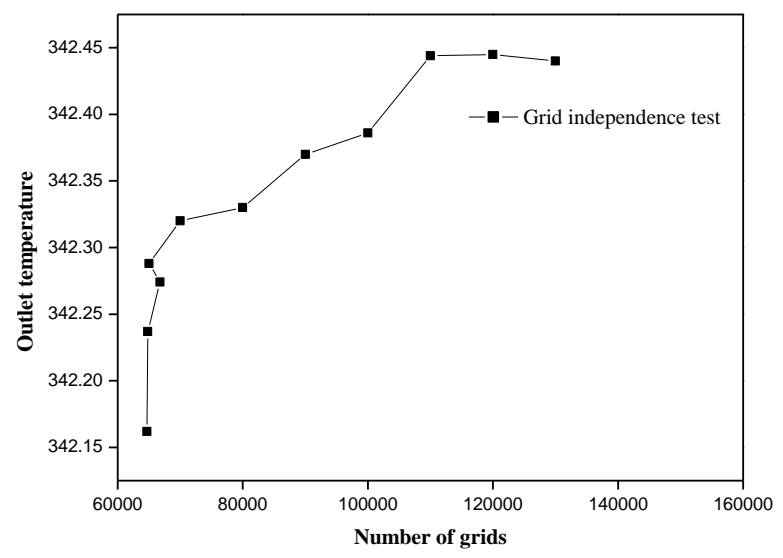

(b)

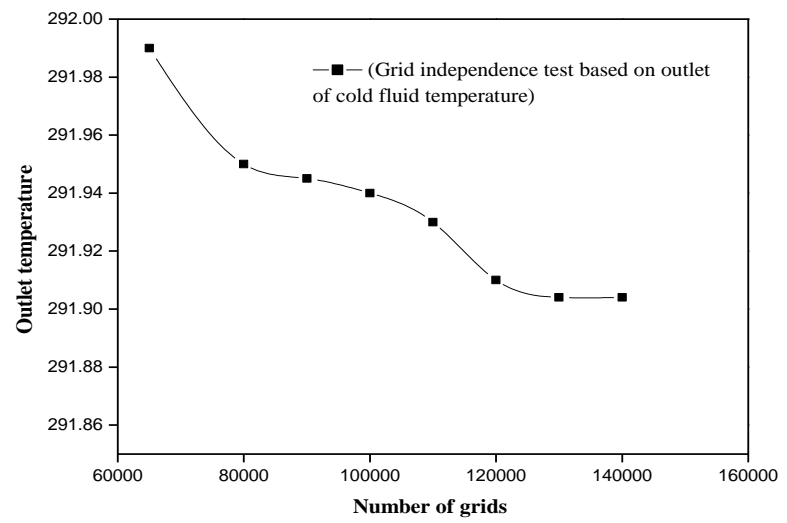

(c)

Figure 3. (a) GIT based on inlet pressure of hot fluid, (b) GIT based on outlet temperature of hot fluid, (c) GIT based on outlet temperature of cold fluid 
In the present study, initializing from $\mathrm{D} / \mathrm{d}=10$ with assumptions of insulated outer wall, inlet velocity of hot fluid as $1.5072 \mathrm{~m} / \mathrm{s}(\mathrm{Re}=10000)$, temperature at $355 \mathrm{~K}$ and variation of grid size from 65770 to 139770 , the GIT is performed based on inlet pressure of hot fluid, outlet temperature of hot fluid and outlet temperature of cold fluid. From Fig. 3 (a), it can be observed that the results are independent after 137617, which shows that the results are independent of the grid after the specified value. Also from Fig. 3 (b) and (c), it can be seen that the results are independent after 138726 number of divisions, showing that the results are independent of the grid.

\section{Governing Equations and Boundary Conditions}

The models were analyzed using constant wall heat flux $(20000 \mathrm{~W} / \mathrm{m} 2)$ and temperature $(300 \mathrm{~K})$ for both laminar and turbulent flows. The working fluid is assumed to be water and the corresponding properties of water are shown in Table. 1 below. The initial temperature and pressure of the fluid are taken to be $360 \mathrm{~K}$ and $1 \mathrm{~atm}$.

Table.1 Properties of the working fluid: water

\begin{tabular}{|l|l|l|}
\hline Sl. No. & \multicolumn{1}{|c|}{ Particulars } & \multicolumn{1}{c|}{ Value } \\
\hline 1. & Density $(\rho)$ & $1000 \mathrm{~kg} / \mathrm{m}^{3}$ \\
\hline 2. & Thermal Conductivity $(\mathrm{k})$ & $0.6 \mathrm{~W} / \mathrm{m}-\mathrm{K}$ \\
\hline 3. & Specific heat $\left(\mathrm{C}_{\mathrm{p}}\right)$ & $4.182 \mathrm{~kJ} / \mathrm{kg}-\mathrm{K}$ \\
\hline 4. & Dynamic viscosity $(\mu)$ & $0.001 \mathrm{~kg} / \mathrm{m}-\mathrm{s}$ \\
\hline
\end{tabular}

The following are the boundary conditions for the present study:

(a) The inlet velocity of the fluid are assumed to be $0.6 \mathrm{~m} / \mathrm{s}, 0.8 \mathrm{~m} / \mathrm{s}, 1 \mathrm{~m} / \mathrm{s}$ and $1.2 \mathrm{~m} / \mathrm{s}$.

(b) The inlet gauge pressure are assumed to be $5000 \mathrm{~N} / \mathrm{m}^{2}, 10000 \mathrm{~N} / \mathrm{m}^{2}, 15000 \mathrm{~N} / \mathrm{m}^{2}$ and $20000 \mathrm{~N} / \mathrm{m}^{2}$

The flow was taken to be steady and incompressible and the density of the fluid is constant throughout the computational domain. The effect of conduction on the tube material is small. SIMPLE algorithm is used for the pressure correction approach and the relaxation factor has been kept to its default values (Pressure: 0.3; Momentum: 0.7; Energy: 01; Density: 01; Body force: 01). k-epsilon model is being used as the turbulence model. The governing equations for the study we shown in equations (1) to (7)

Continuity equation

$$
\frac{\partial(\rho u)}{\partial x}+\frac{\partial(\rho v)}{\partial y}+\frac{\partial(p w)}{\partial z}=0
$$

Navier-Stokes field equation (Only equation is given below)

$$
\rho\left(u \frac{\partial u}{\partial x}+v \frac{\partial u}{\partial y}+w \frac{\partial u}{\partial z}\right)=p x-\frac{\partial \rho}{\partial x}+\frac{1}{3} \mu \frac{\partial}{\partial x}\left(\frac{\partial u}{\partial x}+\frac{\partial v}{\partial y}+\frac{\partial w}{\partial w}\right)+\mu \nabla^{2} \mathrm{u}
$$

Energy equation

$$
\rho C \rho\left(u \frac{\partial T}{\partial x}+v \frac{\partial T}{\partial y}+w \frac{\partial T}{\partial z}\right)=\left(u \frac{\partial \rho}{\partial x}+\frac{\partial \rho}{\partial y}+\frac{\partial \rho}{\partial w}\right)+k \nabla^{2} T+\mu \varnothing
$$

where $\varnothing$ is the Rayleigh dissipation function and is given by 


$$
\varnothing=2\left[\left(\frac{\partial u}{\partial x}\right)^{2}+\left(\frac{\partial v}{\partial y}\right)^{2}+\left(\frac{\partial w}{\partial z}\right)^{2}\right]+\left[\left(\frac{\partial u}{\partial y}+\frac{\partial v}{\partial x}\right)^{2}+\left(\frac{\partial v}{\partial z}+\frac{\partial w}{\partial y}\right)^{2}+\left(\frac{\partial w}{\partial x}+\frac{\partial u}{\partial z}\right)^{2}\right]-\frac{2}{3}\left[\frac{\partial u}{\partial x}+\frac{\partial v}{\partial y}+\frac{\partial w}{\partial z}\right]
$$

Heat transfer coefficient

$$
h=\frac{-k \frac{\partial T}{\partial x}}{T_{w}-T_{f}}
$$

Nusselt number

$$
N u=\frac{\frac{\partial T}{\partial x} d_{h}}{T_{w}-T_{f}}
$$

Critical Reynolds number as per the correlation given by Schmidt (1967)

$$
\operatorname{Re}_{c r}=2300\left[1+8.6 \frac{d}{D}^{0.45}\right]
$$

\section{Validation of Computational Tool}

A validation is performed with the computational tool and using the experimental data from Verma $\mathrm{T}$. $\mathrm{N}$ et al. (2017) [4]. Using the geometry of the experimental analysis,

standard tube of Dinner $($ inlet $)=25.4 \mathrm{~mm}$, Dinner $($ outlet $)=31.4 \mathrm{~mm}$, Douter (inlet) $=50.8 \mathrm{~mm}$ and Douter (outlet) $=55.8 \mathrm{~mm}$ with length of pipe as $2000 \mathrm{~mm}$, variation of Reynolds number between 5000-17,000, galvanized iron as tube material, mass flow rate of hot fluid and cold fluid were taken as $0.04-0.14 \mathrm{~kg} / \mathrm{s} \& 0.03-0.13 \mathrm{~kg} / \mathrm{s}$ respectively, an identical model is constructed on the computational tool. Standard $\mathrm{k}-\varepsilon$ model is used for the numerical work.

The results of variation of (a) heat transfer co-efficient and (b) Nusselt number with Reynolds number is shown in Fig. 4. From the figures, it can be seen that the results of the computational tool is quite close to that of the experimental results. Hence the results of both experimental and computational are in good agreement. Thus, the computational tool can be effectively used for the study.

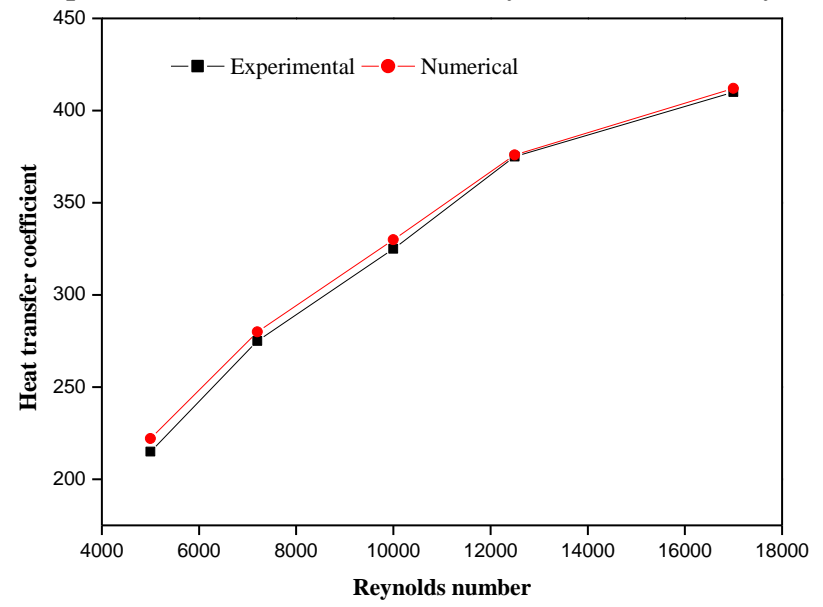

(a)

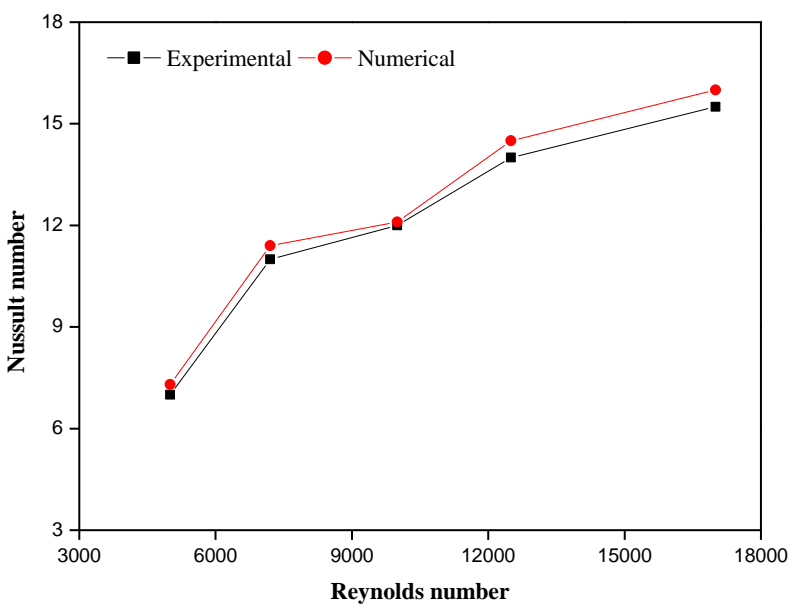

(b)

Figure 4. Validation of experimental and numerical results for (a) heat transfer coefficient and (b) Nusselt number with Reynolds number 


\section{RESULTS AND DISCUSSION Pressure and Temperature Contours}
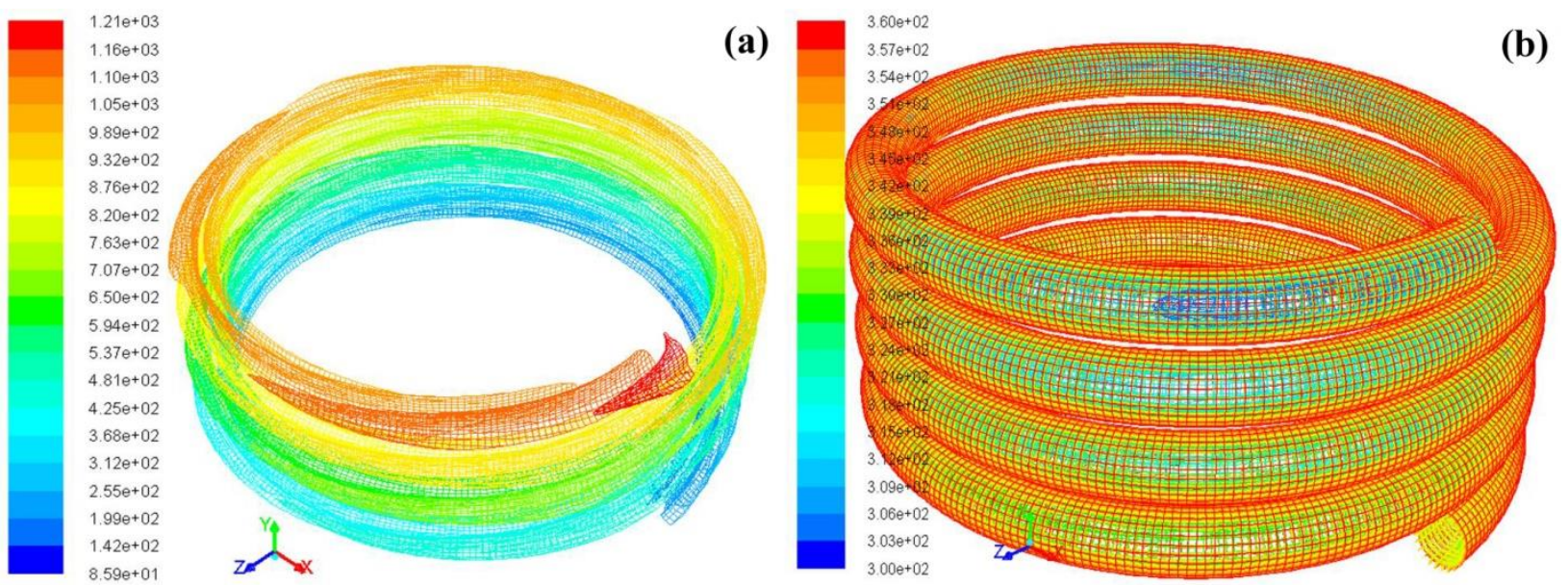

Figure 5. (a) Pressure and (b) temperature contour distribution of tube for constant wall temperature

Fig. 5 shows the distribution of pressure and temperature contours respectively for the constant wall temperature at inlet velocity of $0.6 \mathrm{~m} / \mathrm{s}$ and turbulent flow. The Fig 5 (a) shows that the pressure distribution (pascals) on the helical tubes are more on the upper region, while less effect is being observed in the lower regions. Again, from Fig. 5 (b), the temperature (kelvin) contour shows that the whole length of the tube is subjected to the heat.

\section{Variable Pressure Inlet and Constant Wall Temperature}
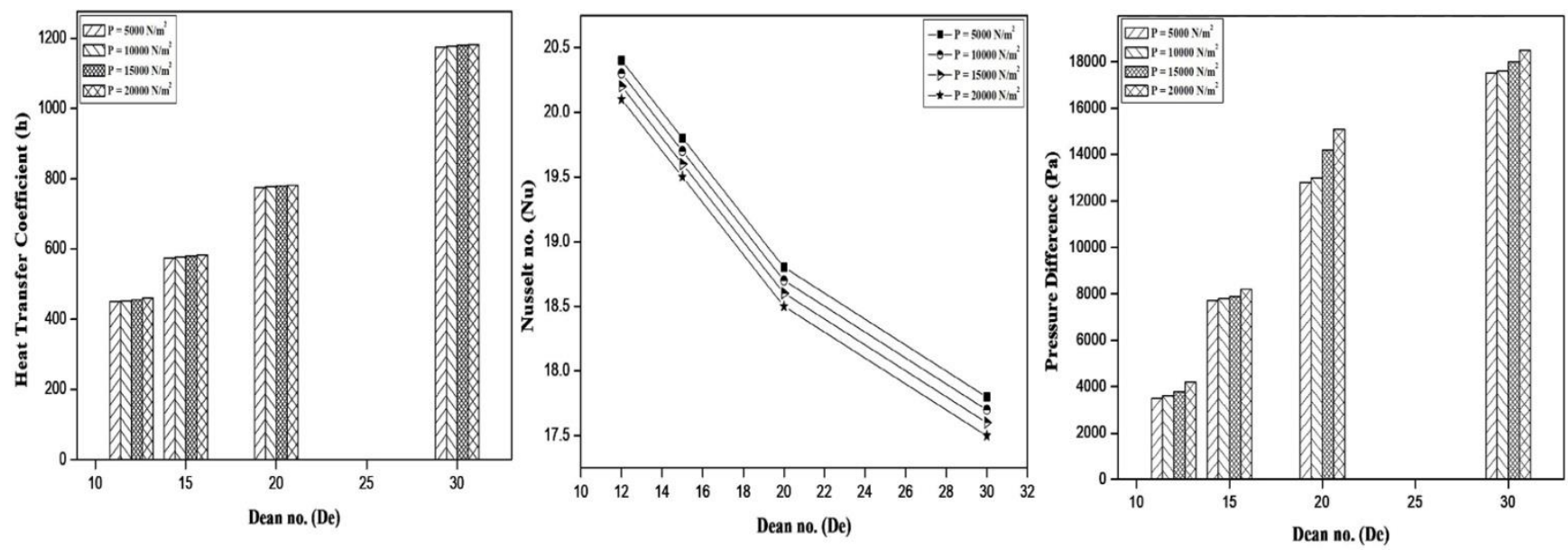

Figure 6. Pressure inlet-constant wall-laminar

Fig. 6 shows the variation of the variation of heat transfer coefficient, Nusselt number and Pressure with Dean number for different pressure inlet, constant wall temperature and laminar flow. From the figure it can be noted that there is slight change in the Nusselt number with change in the inlet pressure in Laminar flow. The heat transfer is directly proportional to the Dean number and hence, maximum heat transfer is observed at maximum value of Dean number, while gradual decrease in $\mathrm{Nu}$ is observed at all values of pressure with increasing Dean number. Less 
change is observed with variation in inlet pressure, though the overall effect in the increase of pressure difference is observed with increase in Dean number during laminar flows.
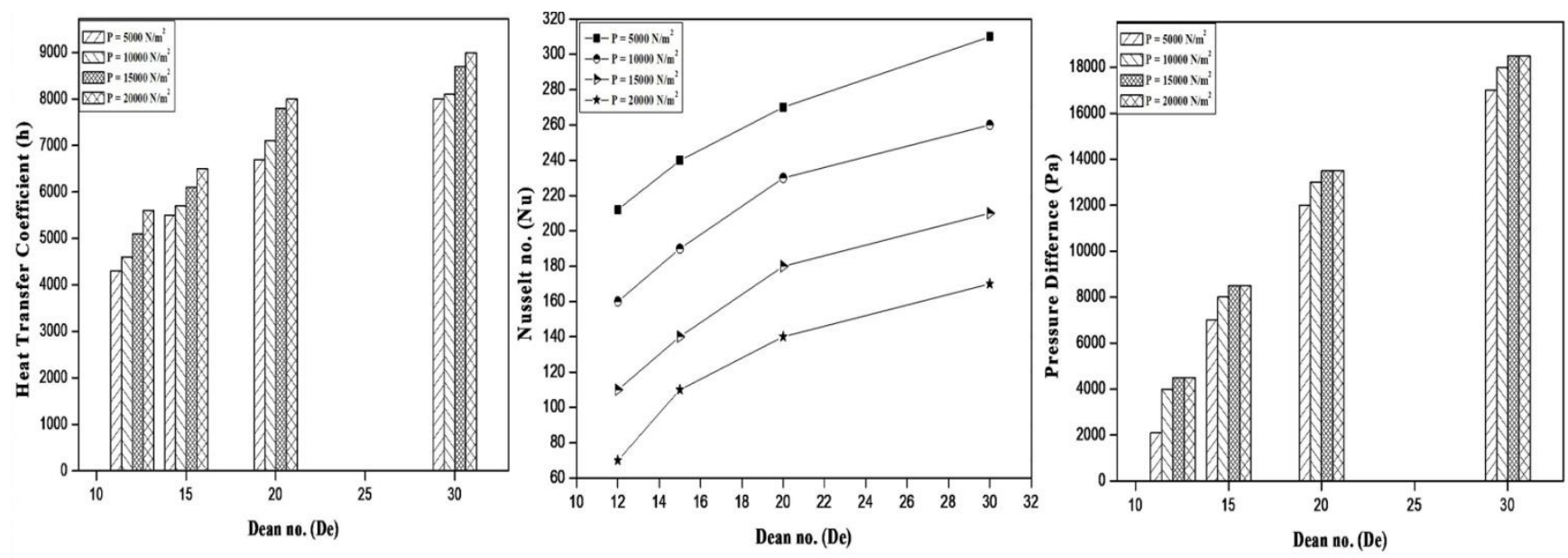

Figure 7. Pressure inlet-constant wall-turbulent

The variation of heat transfer coefficient, Nusselt number and Pressure with Dean number for different pressure inlet, constant wall temperature and turbulent flow is shown in Fig. 7. From the graph, is can be seen that there is increase in Nusselt number with increase in Dean number and pressure. Accordingly, the heat transfer coefficient also increases with increase in inlet pressure. Thus, helical tubes will have higher performance, with increasing Dean number. In turbulent flow conditions, there is increase in all the parameters under study with increase in Dean number. Heat transfer co-efficient increases with increase in pressure inlet while, reduction in Nusselt number is observed. Increase in pressure difference with increase in inlet pressure is observed and for all values of inlet pressure, the pressure difference increases with Dean number.

\section{Variable Pressure Inlet and Constant Heat Flux}
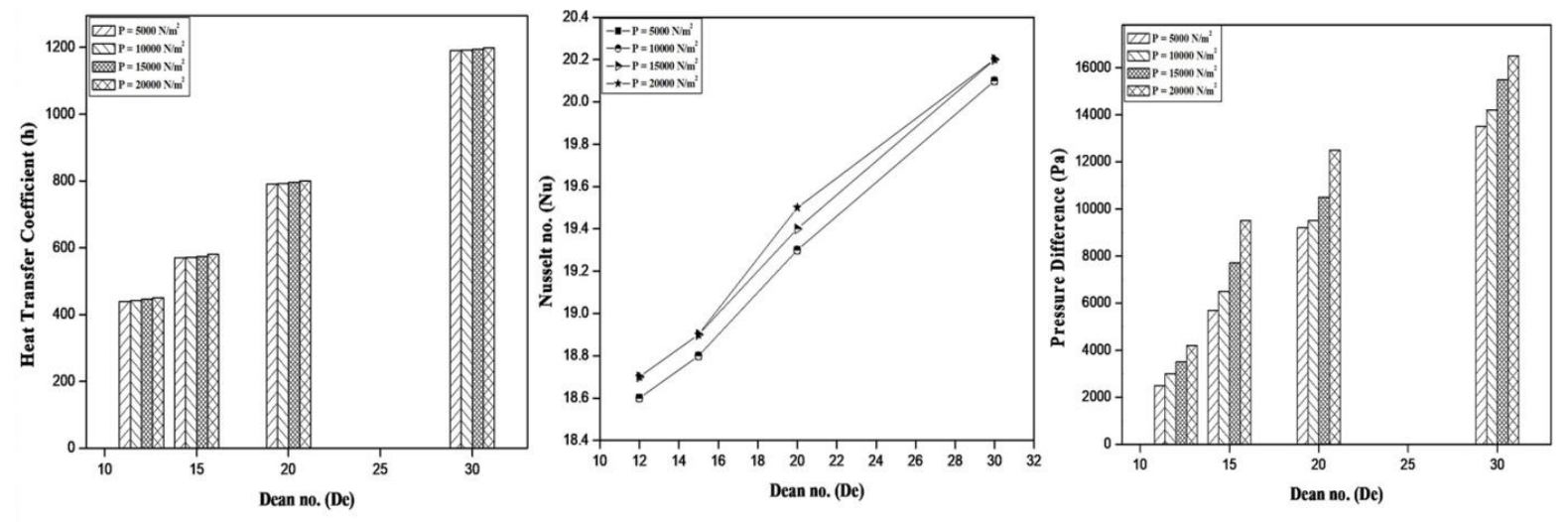

Figure 8. Pressure inlet-constant heat flux-laminar 

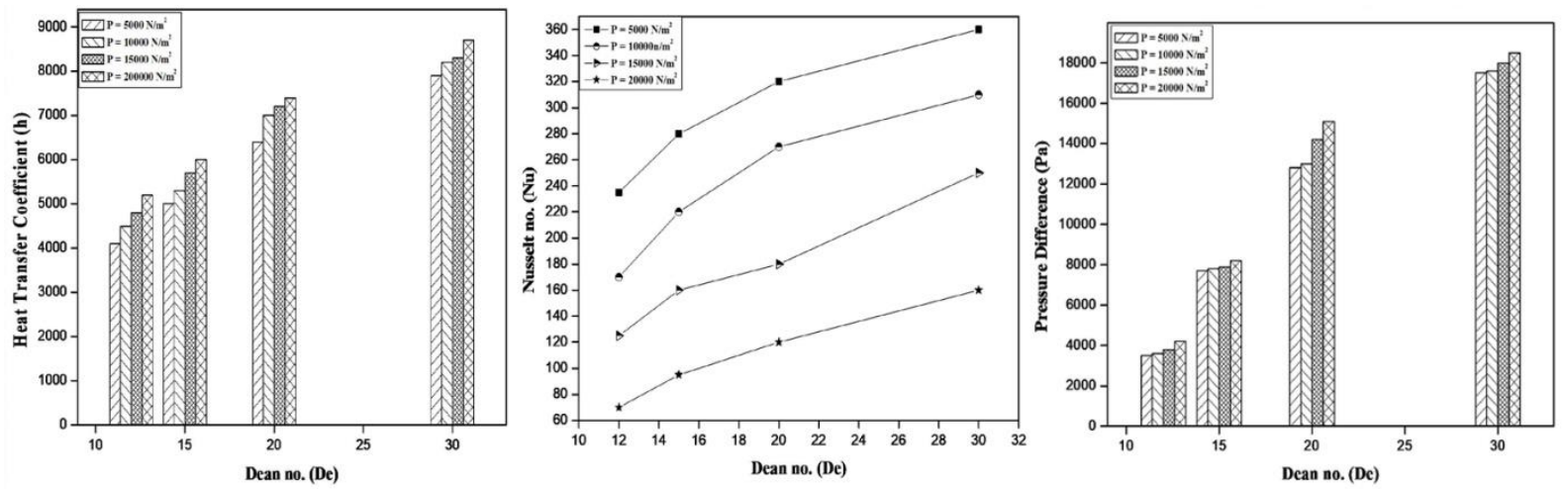

Figure 9. Pressure inlet-constant heat flux-turbulent

The variation of heat transfer coefficient, Nusselt number and Pressure with Dean number for different pressure inlet and constant heat flux is shown in Fig. 8 (laminar flow) and Fig. 9 (turbulent flow) respectively. The computational study shows higher value of Nusselt number in helical tubes, as compared to straight tubes. During constant heat flux conditions, in both laminar and turbulent flow conditions, the heat transfer co-efficient and pressure difference increases with increase in Dean number. In laminar flow, it can be observed that the Nusselt number for variable values of pressure inlet have less significant effect at lower Dean number. An increase in Nu is observed in increasing Dean number.

\section{Variable Velocity Inlet and Constant Wall Temperature}
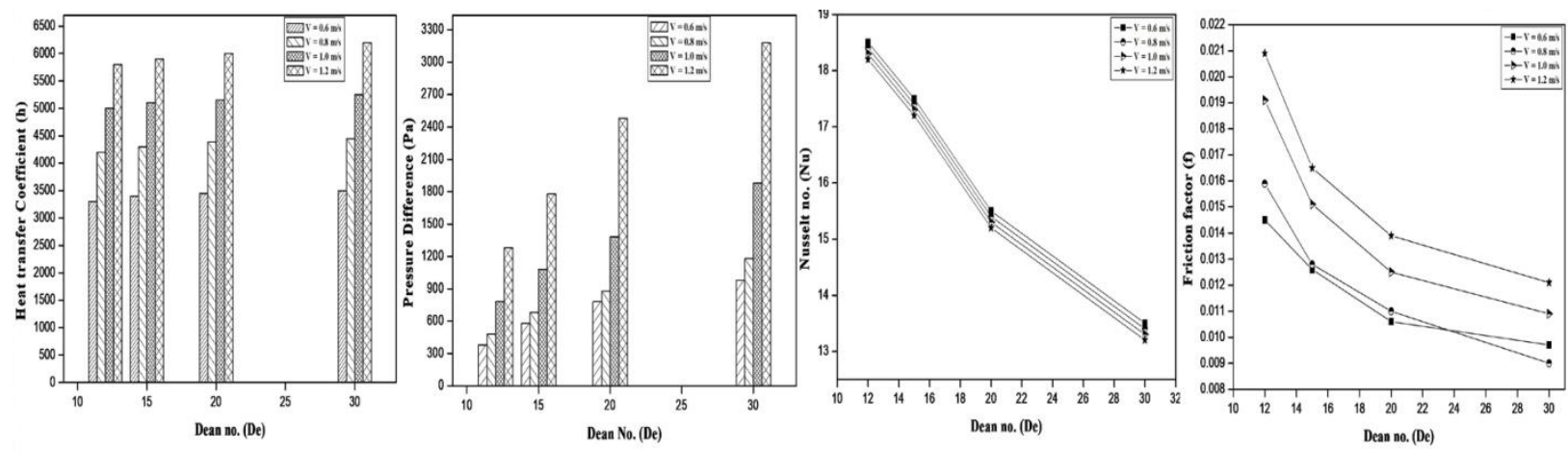

Figure 10. Velocity inlet-constant wall temperature-laminar

The variation of heat transfer coefficient, Pressure difference, Nusselt number and friction factor with Dean number at variable velocity and constant wall, laminar flow is shown in Fig. 10. There is slight change in the heat transfer coefficient, with increase in Dean number. It can be observed that there is increase in pressure differences with the flow with increasing Dean number and velocity of flow. From the graph between Nusselt number and Dean number, it can be noted that the differences in the decrease in the Nusselt number due to increasing Dean number for all flow of different velocity is identical. This shows that the changes in the Nusselt number are very low, when increasing Dean number and variation of flow velocity. At lower flow velocity it can be observed that the effect of Dean number is very less, while on the contrary very little change of from $5675 \mathrm{~W} / \mathrm{m} 2 \mathrm{~K}$ at $\mathrm{D} / \mathrm{d}$ of 12 is seen to increase up to $6017 \mathrm{~W} / \mathrm{m} 2 \mathrm{~K}$ at D/d of 20 , while the value of heat transfer co-efficient is observed to be about 6176 $\mathrm{W} / \mathrm{m} 2 \mathrm{~K}$ at $\mathrm{D} / \mathrm{d}$ of 30 . A similar reduction trend in $\mathrm{Nu}$ is observed while increasing the $\mathrm{D} / \mathrm{d}$ ratio for all inlet velocity values. While the friction factor increase with increase in flow velocity and decreases with increase in Dean number at laminar flow with constant wall temperature. 

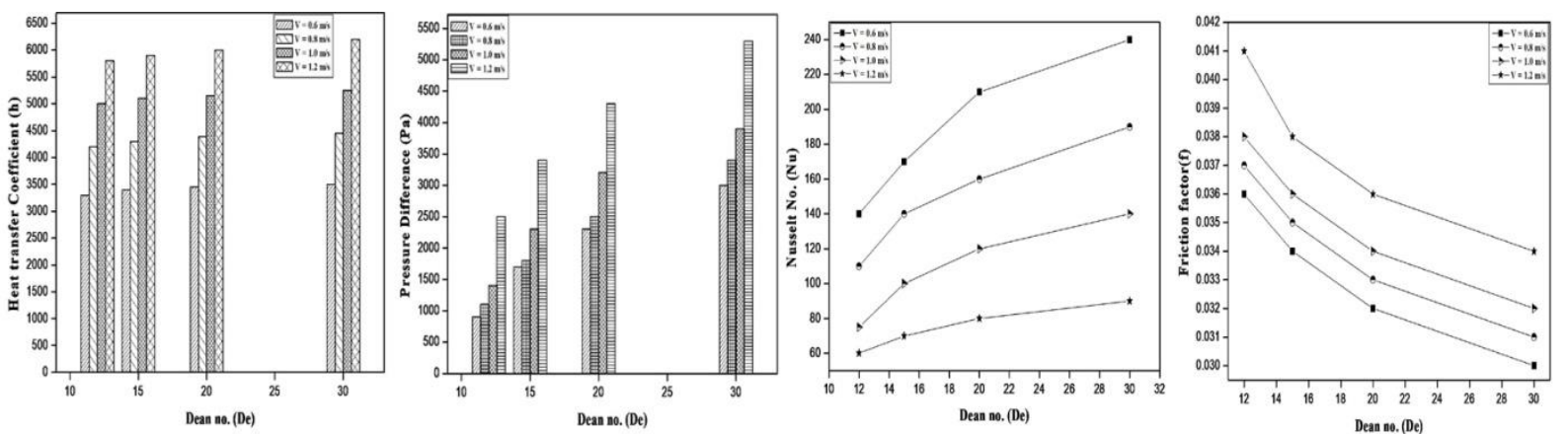

Figure 11. Velocity inlet-constant wall temperature-turbulent

Fig. 11 shows the variation of heat transfer coefficient, Pressure difference, Nusselt number and friction factor with Dean number at variable velocity and constant wall, turbulent flow. From the graph it is clear that there is increase in Nusselt number, with increase in Dean number. Similar trend like laminar flow can also be observed in turbulent flow for variable flow velocity at constant wall temperature, but $\mathrm{Nu}$ increases with increase in Dean number and decreases with increasing flow velocity.

\section{Variable Velocity Inlet and Constant Heat Flux}
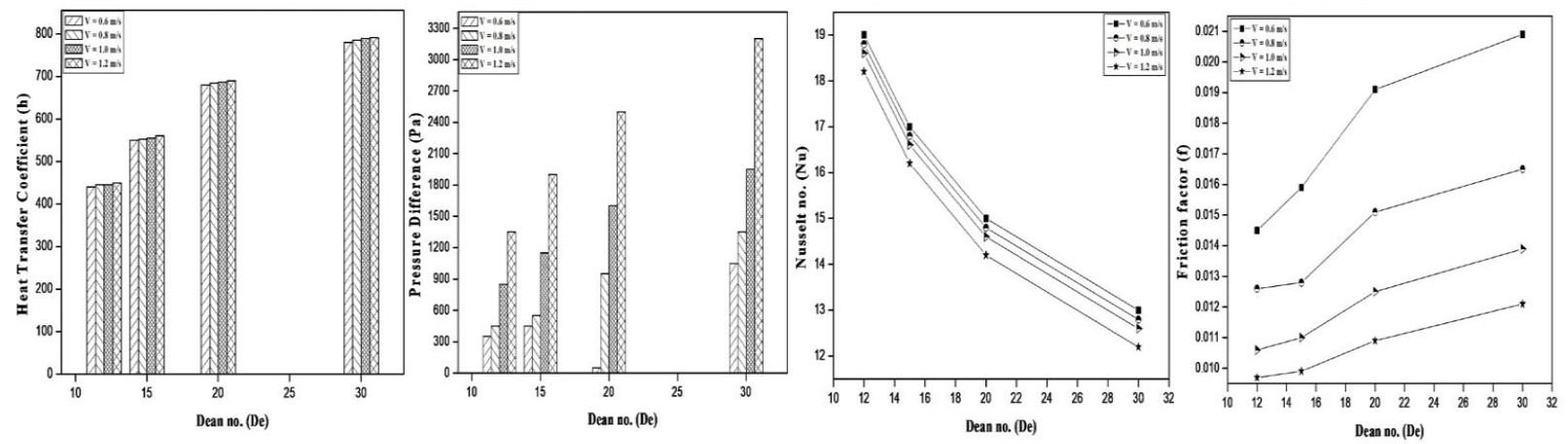

Figure 12. Velocity inlet-constant heat flux-laminar

Fig. 12 shows the variation of Dean number with heat transfer coefficient, Pressure difference, Nusselt number and friction factor at variable inlet and constant heat flux with laminar flow. It can be observed that the heat transfer co-efficient increases with increase in Dean number for all values, while Nusselt number decreases with increase in Dean number. The increase in velocity increases the parameters like heat transfer co-efficient and pressure difference. Lower values of Nusselt number and friction factor is also observed with increase in pressure of the fluid flow. The effect of variable velocity inlet at constant heat flux and laminar flow for heat transfer co-efficient is seen to be negligible since at all velocity profiles, the heat transfer co-efficient is almost constant, though it increase with increase in Dean number. The friction factor during laminar flow decrease with increase in velocity of flow, yet increase with increasing Dean number. 

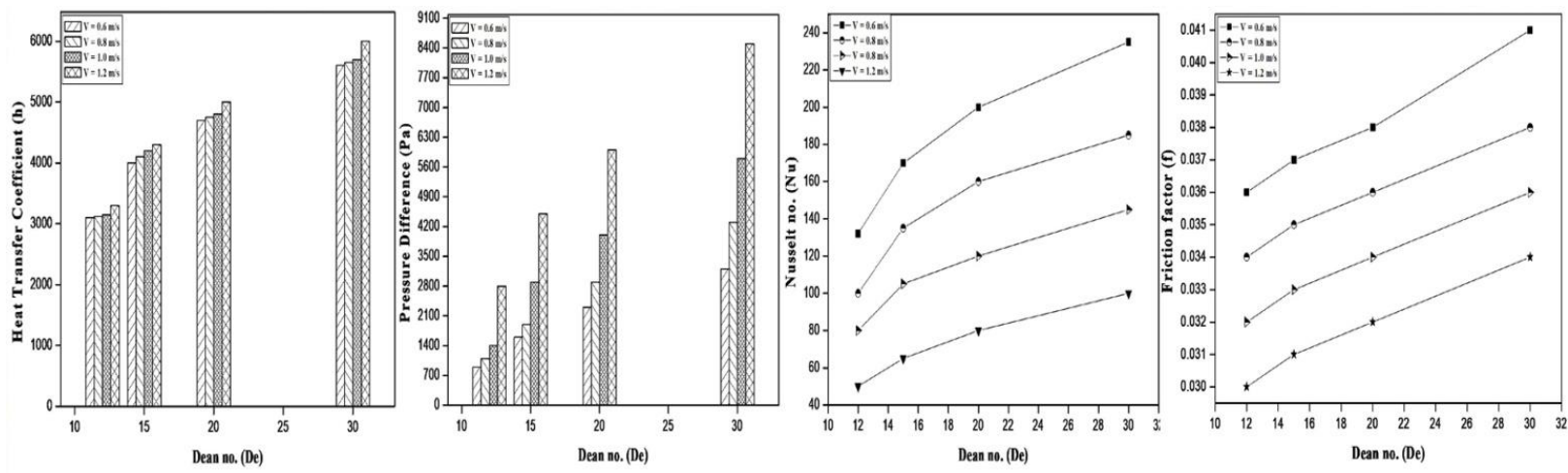

Figure 13. Velocity inlet-constant heat flux-turbulent

The variation of heat transfer coefficient, Pressure difference, Nusselt number and Friction factor at variable inlet and constant heat flux with turbulent flow with Dean number is shown in Fig. 13. It can be observed that the increase in Dean number results in increase in corresponding values. The increase in velocity increases the heat transfer co-efficient and pressure difference. But the Nusselt number decreases with decrease in velocity. Similar trend can be observed for Friction factor also.

\section{CONCLUSION}

Heat transfer phenomenon and fluid flow is studied using commercially available computational tool. The corresponding effects of inlet mass flow rate, pressure at inlet and ratio of curvature (Dean number) is studied. The following conclusions are drawn from the study:

- The results of Nusselt number largely depends on the Dean number. The increase in Nusselt number is observed with the increase in Dean number and mass flow rate.

- The friction factor is more for Turbulent flow, as compared to laminar flow in all cases.

- The computational tool can be used for studying complex and expensive study, which are rather undesirable for experimental study.

\section{NOMENCLATURE}

Ac flow area, $\mathrm{m} 2$

As surface area, $\mathrm{m} 2$

Cp specific heat, $\mathrm{J} / \mathrm{kgK}$

d diameter of pipe, $\mathrm{mm}$

dh hydraulic diameter, $\mathrm{mm}$

D coil diameter, $\mathrm{mm}$

De Dean Number

$\mathrm{f}$ friction factor

G mass velocity, $\mathrm{m} / \mathrm{s}$

h heat transfer coefficient, W/m2K

$\mathrm{H}$ pitch of coil, mm

j Colburn factor

$\mathrm{k}$ thermal conductivity, $\mathrm{W} / \mathrm{mK}$

$\mathrm{L} \quad$ length of pipe, $\mathrm{m}$

$\mathrm{m}$ mass flow rate, $\mathrm{kg} / \mathrm{s}$

n number of turns

$\mathrm{Nu} \quad$ Nusselt Number

$\mathrm{p}$ pressure, $\mathrm{N} / \mathrm{m} 2$

Pr Prandtl Number

Q heat flux, W/m2

Re Reynolds Number 


$\begin{array}{ll}\text { St } & \text { Stanton Number } \\ \text { T } & \text { Temperature, K } \\ \text { u, v, w } & \text { velocity along X-axis, Y-axis and Z-axis, m/s } \\ \text { V } & \text { flow velocity, m/s } \\ \text { Vs } & \text { wetted volume, m3 } \\ \text { X, y, z } & \text { coordinates } \\ \text { X } & \text { body force }\end{array}$

Greek symbols

$\beta \quad$ surface area density, $\mathrm{m} 2 / \mathrm{m} 3$

$\rho \quad$ density, $\mathrm{kg} / \mathrm{m} 3$

$\mu \quad$ dynamic viscosity, $\mathrm{kg} / \mathrm{ms}$

$\varphi \quad$ Rayleigh dissipation factor

$\begin{array}{ll}\text { Subscripts } \\ \text { cr } & \text { critical } \\ \text { d } & \text { diameter } \\ \text { f } & \text { fluid } \\ \text { w } & \text { wall }\end{array}$

\section{REFERENCES}

[1] B BD. Experimental and computational investigation of the spiral ground heat exchangers for ground source heat pump applications Coefficient of Performance. Appl Therm Eng. 2017; 121:908-921. doi:10.1016/j.applthermaleng.2017.05.002.

[2] Alfarawi S, Mahmoud S. Transient investigation of mini-channel regenerative heat exchangers: Combined experimental and CFD approach. Appl Therm Eng. 2017. doi:10.1016/j.applthermaleng.2017.07.038.

[3] Sun XY, Dai YJ, Ge TS, et al. Comparison of performance characteristics of desiccant coated air-water heat exchanger with conventional air-water heat exchanger - experimental and analytical investigation Accepted Manuscript. 2017. doi:10.1016/j.energy.2017.03.078.

[4] Verma TN, Nashine P, Singh DV, Singh TS, Panwar D. ANN: Prediction of an experimental heat transfer analysis of concentric tube heat exchanger with corrugated inner tubes. Appl Therm Eng. 2017;120. doi:10.1016/j.applthermaleng.2017.03.126.

[5] Maakoul A El, Metoui M El, Abdellah A Ben, Meziane M. Numerical investigation of thermohydraulic performance of air to water double-pipe heat exchanger with helical fins. Appl Therm Eng. 2017. doi:10.1016/j.applthermaleng.2017.08.024.

[6] Sharifi K, Sabeti M, Rafiei M, Mohammadi AH, Shirazi L. Computational Fluid Dynamics (CFD) Technique to Study the Effects of Helical Wire Inserts on Heat Transfer and Pressure Drop in a Double Pipe Heat Exchanger. Appl Therm Eng. 2017. doi:10.1016/j.applthermaleng.2017.08.146.

[7] Sabek S, Tiss F, Chouikh R, Guizani A. Numerical investigation of heat and mass transfer in partially blocked membrane based heat exchanger: effects of obstacles forms. Appl Therm Eng. 2017. doi:10.1016/j.applthermaleng.2017.11.019.

[8] Lee MS, Li Z, Ling J, Aute V. A CFD Assisted Segmented Control Volume Based Heat Exchanger Model for Simulation of Air-to-Refrigerant Heat Exchanger with Air Flow Mal-distribution. Appl Therm Eng. 2017. doi:10.1016/j.applthermaleng.2017.11.094.

[9] Abay K, Colak U, Yüksek L. Computational fluid dynamics analysis of flow and combustion of a diesel engine. Journal of Thermal Engineering. 2018; 4 (2):1878-1895.

[10] Gül M. Z, Köten H, Yılmaz M, Savcı İ. H. Advanced numerical and experimental studies on CI engine emissions. Journal of Thermal Engineering. 2018: 4 (4): 2234-2247.

[11] A. Gómez, C. Montañés, M. Cámara, A. Cubero, N. Fueyo, and J. M. Muñoz. An OpenFOAM-based model for heat-exchanger design in the Cloud. Appl. Therm. Eng.2018; 139: 239-255.

[12] Ł. Amanowicz and J. Wojtkowiak. Validation of CFD model for simulation of multi-pipe earth-to-air heat exchangers (EAHEs) flow performance. Therm. Sci. Eng. Prog. 2018; 5: 44-49.

[13] S. Kim et al., Comparison of CFD simulations to experiment for heat transfer characteristics with aqueous Al2O3nanofluid in heat exchanger tube. Int. Commun. Heat Mass Transf. 2018; 95: 123-131. 
[14] K. Somasekhar, K. N. D. Malleswara Rao, V. Sankararao, R. Mohammed, M. Veerendra, and T. Venkateswararao. A CFD Investigation of Heat Transfer Enhancement of Shell and Tube Heat Exchanger Using Al2o3-Water Nanofluid. Materials Today: Proceedings, 2018; 5(1): 1057-1062.

[15] J. Ge, W. Tian, S. Qiu, and G. H. Su. CFD investigation on thermal hydraulics of the passive residual heat removal heat exchanger (PRHR HX). Nucl. Eng. Des. 2018; 327:139-149.

[16] C. Pan, T. Zhang, J. Wang, and Y. Zhou. CFD study of heat transfer and pressure drop for oscillating flow in helical rectangular channel heat exchanger. Int. J. Therm. Sci. 2018; 129:106-114.

[17] S. Mehmet, K. Aykut, and Hasan Köten. Thermal analysis and optimization of high power led armature. Thermal Sci. 2018; 103:238-248, doi: 10.2298/TSCI170704238S

[18] Hasan Köten and M. Z. Gul. Multidimensional Modeling of Compressed Bio Gas (CBG) Engine for Ultra Low Emission. Marmara Journal of Pure and Applied Sciences. 2014; 26(2) : 47-55, doi: http://dx.doi.org/10.7240/MJS.2014267516

[19] Hasan Köten. Performance Analysis of a Diesel Engine within a Multi-Dimensional Framework. Journal of Thermal Engineering. 2014; 4(4): 2075-2082, doi: 10.18186/journal-of-thermal-engineering.414153

[20] Hasan Köten, M. Yilmaz, and M. Z. Gul. A CFD Study and Geometrical Improvement on Heavy Duty Diesel Engine for Ultra-Low Emissions IMECE2010, November 12th - 15th 2010, Vancouver, Canada

[21] Ünlügençoğlu K, Yurtseven A, Alarçin F. Shipping emission dispersions of the port of ambarli via CFD modelling. Journal of Thermal Engineering. 2020; 6 (2):1-14.

[22] Prakash O, Arora R. Characterization of multi-phase particle slurry in thermal power plants using computational fluid dynamics. Journal of Thermal Engineering. 2020; 6 (1):187-203.

[23] Sener R, Ozdemir MR, Yangaz MU. Effect of the geometrical parameters in a domestic burner with crescent flame channels for an optimal temperature distribution and thermal efficiency. Journal of Thermal Engineering. 2019; 5 (6):171-183.

[24] Netam N, Sanyal S, Bhowmick S. Assessing the impact of passive cooling on thermal comfort in LIG house using CFD. Journal of Thermal Engineering. 2019; 5 (5):414-421.

[25] Acikgoz O. Determination of convective, radiative, and total heat transfer characteristics over a radiant heated ceiling: A computational approach. Journal of Thermal Engineering. 2019; 5 (5):372-384.

[26] Bayareh M, Nouurbakhsh A. Study on the effect of porous plates on the tank bottom on the boiling process. Journal of Thermal Engineering. 2019; 5 (3):149-156.

[27] Kaya H, Ekiciler R, Arslan K. CFD analysis on laminar forced convective heat transfer for TiO2/water nanofluid in a semi-circular cross-sectioned micro-channel. Journal of Thermal Engineering. 2019; 5 (3):123-137.

[28] Menni Y, Azzi A, Zidani C. CFD simulations of thermo-aeraulic fields in a channel with multiple baffle plates. Journal of Thermal Engineering. 2018; 4 (6):2481-2495.

[29] Gul MZ, Koten H, Yilmaz M, Savci IH. Advanced numerical and experimental studies on CI engine emissions. Journal of Thermal Engineering. 2018; 4 (4):2234-2247.

[30] Singh T S, Verma T N. 2019. Impact of Tri-Fuel on Compression Ignition Engine Emissions: Blends of Waste Frying Oil-Alcohol-Diesel. In: Agarwal A., Gautam A., Sharma N., Singh A. (eds) Methanol and the Alternate Fuel Economy. Energy, Environment, and Sustainability. Springer, Singapore

[31] Rajak U, Nashine P, Verma T N, Pugazhendhi A. Performance, combustion and emission analysis of microalgae Spirulina in a common rail direct injection diesel engine. Fuel 2019; 255: 115855.

[32] Singh T S, Verma T N. Biodiesel production from Momordica Charantia (L.): Extraction and engine characteristics. Energy 2019; 189: 116198

[33] Koten H. Performance analysis of a diesel engine with multi-dimensional framework. Journal of Thermal Engineering. 2018; 4 (4):2201-2210. 